\title{
La abolición de las corridas de toros en Cataluña
}

\section{Anna Mulà}

Licenciada en derecho

Miembro de la Comisión Promotora de la Iniciativa Legislativa Popular

\section{Resumen}

Este artículo resume el proceso de la iniciativa legislativa popular aprobada por el Parlamento de Cataluña que prohíbe las corridas de toros en esta Comunidad Autónoma.

\section{Palabras clave}

Iniciativa legislativa popular; Corridas de toros; Parlamento; Prohibición;

\section{Abstract}

This article outlines the process of the popular legislative initiative passed by the Catalan Parliament banning bullfights in this region.

\section{Key words}

Popular Legislative Initiative; Bullfighting; Parliament; Ban

\section{Introducción}

La ley sobre la abolición de las corridas de toros en Cataluña, que entra en vigor el 1/1/2012, se ha publicado en el BOE de 23 de agosto de $2010^{1}$ (así como en el «Diario Oficial de la Generalidad de Cataluña» número 5687, de 6 de agosto de 2010) después de que el pasado 28 de julio Parlamento de Cataluña la aprobara por mayoría absoluta. El artículo primero de la ley incluye la adición de una letra, la $f$, en el apartado 1 del artículo 6 del Texto refundido de la Ley de protección de los animales, aprobado por el Decreto legislativo 2/2008, de 15 de abril, ${ }^{2}$ (que se refiere a la prohibición de peleas de animales y otras actividades), con el texto siguiente: "f) Las corridas de toros y los espectáculos con toros que incluyan la muerte del

\footnotetext{
${ }^{1}$ Ley 28/2010, de 3 de agosto, de modificación del artículo 6 del texto refundido de la Ley de protección de los animales, aprobado por el Decreto legislativo 2/2008. http://www.derechoanimal.info/bbdd/Documentos/791.pdf

${ }^{2}$ http://www.derechoanimal.info/bbdd/Documentos/458.pdf
} 
animal y la aplicación de las suertes de la pica, de las banderillas y del estoque, y también los espectáculos taurinos de cualquier modalidad que tengan lugar dentro y fuera de las plazas de toros, salvo las fiestas con toros o bous a que se refiere el apartado 2". Y en su artículo segundo se suprime la letra a del apartado 2 del artículo 6 del mismo Texto refundido, que queda redactado de la manera siguiente: "2. Quedan excluidas de estas prohibiciones las fiestas con toros o bous sin muerte del animal (correbous) en las fechas y localidades donde tradicionalmente se celebren. En estos casos, está prohibido inferir daño a los animales".

Esta Ley se dicta como consecuencia de una iniciativa legislativa popular (ILP) presentada a instancia de la Plataforma PROU (Basta en catalán), después de constatar el continuado y progresivo rechazo de la sociedad catalana hacia este espectáculo. En Cataluña existe un contexto legal que propicia la continuación de un proceso que se inició con la Ley 3/1988, de 4 de marzo, de protección de los animales, que prohibió la construcción de nuevas plazas de toros en todo el territorio catalán y siguió con la Ley 22/2003, de 4 de julio, de protección de los animales, que además de considerar a los animales organismos dotados de sensibilidad física y psíquica, limitó el acceso a las plazas de los menores de catorce años. Así, con la prohibición de las corridas de toros en todas las modalidades previstas legalmente, a través de la aprobación de esta Ley recientemente publicada en los diarios oficiales ${ }^{3}$, se culmina este proceso legal.

\section{Tramitación y votación de la ILP}

El 11 de noviembre de 2008, el Parlamento de Cataluña admitió a trámite la proposición de Ley para abolir las corridas de toros en dicha Comunidad Autónoma, al considerar que el objeto de la ILP era una materia sobre la que la Generalitat de Cataluña tenía reconocida su competencia y el Parlamento podía legislar. ${ }^{4}$ Inmediatamente después, se inició el plazo de recogida de firmas por los fedatarios acreditados, los cuales reunieron 180.169 rúbricas en 120 días -cuadriplicando el mínimo exigido legalmente de 50.000 firmas-, ${ }^{5}$ circunstancia que

\footnotetext{
${ }^{3}$ Vid. supra, n.1.

${ }^{4}$ Artículo 1 de la Ley 1/2006, de 16 de febrero, de la Iniciativa Legislativa Popular

"Pueden ser objeto de la iniciativa legislativa popular las materias sobre las que la Generalidad tiene reconocida su competencia y el Parlamento puede legislar, de acuerdo con la Constitución y el Estatuto de autonomía, a excepción de las materias que el Estatuto de autonomía reserva a la iniciativa legislativa exclusiva de los diputados, los grupos parlamentarios o el Gobierno, de los presupuestos de la Generalidad y de las materias tributarias."
}

${ }^{5}$ Artículo 3 de la Ley 1/2006, de 16 de febrero, de la Iniciativa Legislativa Popular

"La iniciativa legislativa popular se ejerce por medio de la presentación en la Mesa del Parlamento de una proposición de ley, con el apoyo de las firmas, debidamente autenticadas, de un mínimo de 50.000 personas, que deben cumplir las condiciones establecidas por el artículo 2." 
motivó el inicio de la tramitación parlamentaria de la ILP el 21 de julio de 2009. El 18 de diciembre de 2009 tuvo lugar, en el Pleno del Parlamento, el debate a la totalidad de la proposición de ley, y en atención a que la enmienda a la totalidad fue rechazada, la ILP continuó su tramitación. Este paso fue de suma importancia ya que las fuerzas políticas, siendo representativas de la ciudadanía, permitieron que la ILP fuera debatida en profundidad en sede parlamentaria.

El 3, 4 y 17 de marzo de 2010 tuvieron lugar las comparecencias de expertos, los cuales expusieron de forma justificada las razones que habían de conducir a la invalidación del actual marco jurídico que legaliza las corridas de toros y cuyas opiniones, que son públicas, tienen por finalidad incidir en la decisión de los diputados. La aportación de los 15 comparecientes a favor de la ILP (científicos, etólogos, filósofos, veterinarios, escritores, profesionales del derecho, todos ellos de reconocido prestigio $^{6}$ constituye un legado sin precedentes cuyo testimonio argumental servirá para apuntalar otras aboliciones en territorios donde se celebran corridas de toros. ${ }^{7}$

\footnotetext{
${ }^{6}$ Javier de Lucas. Catedrático de Derecho en la Universidad de Valencia. Director del Colegio de España en París.

Jordi Portabella. Biólogo. Regidor en el Ayuntamiento de Barcelona (ERC).

Jordi Casamitjana. Etólogo (experto en comportamiento animal) graduado en la Universidad de Barcelona. Actualmente es Director de Animal Protection Consultancy (Reino Unido).

Antonio Moreno Ex aficionado taurino. Presidente del Colectivo Andaluz Contra el Maltrato Animal (CACMA).

Espiado Freire. Filóloga y escritora.

Jorge Wagensberg. Profesor, escritor e investigador. Fundador del Museo de la Ciencia de la Fundación La Caixa (Cosmocaixa en la actualidad, galardonado como el Mejor Museo de la Ciencia en Europa en 2005).

Leonardo Anselmi. Miembro de la comisión promotora de la Plataforma PROU. Coordinador de campañas de la Asociación Animalista Libera.

Josep $\mathrm{M}^{\mathrm{a}}$ Terricabras. Catedrático de Filosofía en la Universidad de Girona y Director de la Cátedra Ferrater Mora de Pensament Contemporani.

Jesús Mosterin. Filósofo. Profesor de Investigación del Instituto de Filosofía del CSIC.

Mercedes Cano. Profesora titular de Antropología en el Departamento de Prehistoria, Arqueología, Antropología Social y Ciencias y Técnicas Historiográficas de la Facultad de Filosofía y Letras de Valladolid.

Núria Querol. Bióloga, Médico, Criminóloga. Médico residente en el Hospital Universitario Mútua de Terrassa y Bióloga especialista en Biología Celular y Genética y Biosanitaria.

Norbert Bilbeny. Catedrático de Ética en la Universidad de Barcelona.

José Enrique Zaldivar. Veterinario. Fundador y vicepresidente de AVAT (Asociación de Veterinarios Abolicionistas de la Tauromaquia).

Pablo de Lora. Doctor en Derecho por la Universidad Autónoma de Madrid y profesor titular de Filosofía del Derecho.

Mónica Frassoni. Copresidenta del Grupo de los Verdes / ALE en el Parlamento Europeo
}

7 Comparecencia de Pablo de Lora: http://www.derechoanimal.info/comparecencia-del-prof-pablo-de-loraante-la-comissio-de-medi-ambient-i-habitatge-del-parlament-de-catalunya-4-3-2010-2/ 
Un aspecto a destacar de la tramitación de la ILP, después de oídas todas las comparecencias y de aprobarse en Comisión el texto de la proposición de Ley con las enmiendas correspondientes, es la emisión del dictamen favorable, adoptado por mayoría, del Consejo de Garantías Estatutarias ${ }^{8}$ que es la institución de la Generalitat de Cataluña creada con la finalidad de velar por la adecuación al Estatuto y a la Constitución Española de las disposiciones de la Generalitat, que determinó que el texto de la proposición de ley era respetuoso con la Constitución Española y el Estatuto de Autonomía de Catalunya (EAC). ${ }^{9}$

El dictamen analiza el alcance de la medida prohibitiva que el texto de la Proposición de ley prescribe sobre las corridas de toros, en función de dos variables diferentes: en primer lugar, sobre el alcance de les competencias de la Generalitat en materia de espectáculos públicos (Art. 141.3 del EAC) ${ }^{10}$ y su relación con la competencia relativa a la protección de los animales (Art. 116.1.d del EAC) $;^{11}$ y en segundo lugar, sobre la incidencia que el ejercicio de esta competencia por parte de la Administración autonómica pueda tener sobre el principio rector de la Constitución relativo al acceso a la cultura (Art. 44 de la Constitución Española ${ }^{12}$ ) y los artículos $22.1^{13}$ y 44.5 del EAC ${ }^{14}$. El EAC ha previsto explícitamente la competencia sobre

Comparecencia de Javier de Lucas: http://www.derechoanimal.info/comparecencia-del-prof-javier-de-lucasante-la-comissio-de-medi-ambient-i-habitatge-del-parlament-de-catalunya-4-3-2010/

${ }^{8}$ Ley 2/2009, de 12 de febrero, del Consejo de Garantías Estatutarias.

${ }^{9}$ Ley Orgánica 6/2006, de 19 de julio, de reforma del Estatuto de Autonomía de Cataluña.

${ }^{10}$ Artículo 141.3 del Estatuto de Autonomía de Cataluña

"Corresponde a la Generalitat la competencia exclusiva en materia de espectáculos y actividades recreativas, que incluye, en todo caso, la ordenación del sector, el régimen de intervención administrativa y el control de todo tipo de espectáculos en espacios y locales públicos."

${ }^{11}$ Artículo 116.1 d) del Estatuto de Autonomía de Cataluña

"Corresponde a la Generalitat, respetando lo establecido por el Estado en el ejercicio de las competencias que le atribuye el artículo 149.1.13 y 16 de la Constitución, la competencia exclusiva en materia de agricultura y ganadería. Esta competencia incluye en todo caso: d) La sanidad vegetal y animal cuando no tenga efectos sobre la salud humana y la protección de los animales."

${ }^{12}$ Artículo 44.1 de la Constitución Española

"Los poderes públicos promoverán y tutelarán el acceso a la cultura, a la que todos tienen derecho."

${ }^{13}$ Artículo 22.1 del Estatuto de Autonomía de Cataluña

"Todas las personas tienen derecho a acceder en condiciones de igualdad a la cultura y al desarrollo de sus capacidades creativas individuales y colectivas."

${ }^{14}$ Artículo 44.5 del Estatuto de Autonomía de Cataluña 
espectáculos en el artículo 141.3, según el cual: "Corresponde a la Generalitat la competencia exclusiva en materia de espectáculos y actividades recreativas, que incluye, en todo caso, la ordenación del sector, el régimen de intervención administrativa y el control de todo tipo de espectáculos en espacios y locales públicos". De acuerdo con este nuevo marco estatutario ${ }^{15}$, y en el ejercicio de la competencia exclusiva sobre espectáculos y actividades recreativas, el legislador ha aprobado la Ley 11/2009, del 6 de julio, de regulación administrativa de los espectáculos públicos y las actividades recreativas, que es de aplicación supletoria a la normativa relativa a los espectáculos con animales (Art. 4.3). ${ }^{16}$ La intervención que el Estado desarrolla a través de su legislación sobre las corridas de toros, es decir, la Ley 10/1991, de 4 de abril, sobre potestades administrativas en materia de espectáculos taurinos, ${ }^{17}$ es una regulación de policía administrativa, por lo que la regulación prevista en la legislación estatal sobre la tauromaquia no puede limitar ni cuestionar el alcance de la competencia de la Generalitat sobre espectáculos.

En consecuencia, la competencia exclusiva de la Generalitat sobre espectáculos habilita al legislador catalán para ejercer la potestad normativa a fin de establecer un supuesto de prohibición del espectáculo público, y así garantizar la tutela de un bien jurídico como es la protección de los animales, en el ejercicio de la competencia reconocida en el artículo 116.1.d EAC. Por otra parte, en atención a que la competencia sobre cultura es una competencia de carácter concurrente y que por tanto ambas administraciones públicas, la del Estado y la de la Generalitat, pueden ejercer las mismas funciones, el dictamen establece que la medida prohibitiva de este espectáculo, adoptada en el ejercicio de una competencia exclusiva en materia de espectáculos, no comporta una lesión a los derechos de los ciudadanos en el ámbito de la cultura.

\footnotetext{
"Los poderes públicos deben emprender las acciones necesarias para facilitar a todas las personas el acceso a la cultura, a los bienes y a los servicios culturales y al patrimonio cultural, arqueológico, histórico, industrial y artístico de Cataluña."

${ }^{15}$ Vid. supra, n.9.

${ }^{16}$ Artículo 4.3 de la Ley 11/2009, del 6 de julio, de regulación administrativa de los espectáculos públicos y las actividades recreativas

"Las actividades deportivas, las actividades relacionadas con el juego y las apuestas, las actividades de restauración y los espectáculos con uso de animales son regulados por su normativa específica y, supletoriamente, les es de aplicación la presente Ley."

${ }^{17}$ http://www.derechoanimal.info/bbdd/Documentos/147.pdf
} 
Durante todo el proceso se recibieron manifestaciones de apoyo a la ILP de carácter nacional e internacional Así, destacadas personalidades provenientes del mundo intelectual, académico, artístico, religioso, empresarial, deportivo, científico y literario, y entidades internacionales de defensa de los animales, se dirigieron al Parlamento pidiendo la aprobación de la ILP, apelando a varias causas y motivaciones, siempre conducidas por un principio ético, moral. $^{18}$

El 28 de julio de 2010, día de la votación de la ILP, el Parlamento de Catalunya, aprobando por mayoría absoluta la medida legal prohibitiva, aprovechó una oportunidad histórica para demostrar que la sociedad catalana es sensible y respetuosa con los valores del siglo XXI, enviando un mensaje de compasión universal y de progreso de la humanidad y creando un valioso precedente que esperamos sea imitado en el futuro en aquellos lugares donde se mantiene esta tradición.

\section{El derecho como justificador de la aprobación de la ILP}

Los toros no pueden defenderse por sí mismos dentro del orden jurídico. La idea del progreso y de la evolución ha sido inherente a los humanos y se ha manifestado tanto en

${ }^{18}$ En la web de la Plataforma PROU http://www.prou.cat/ hay los nombres y las fotos de todas las personas mediáticas que han apoyado la campaña; También: Ann Arbor, Michigan, 273 eminentes científicos internacionales, liderados por Kenneth Shapiro, P.h.D. Clinical Psychology, Society and Animals Journal. Ver link: http://www.prou.cat/castellano/n.php?id_noticia=36 La Humane Society Veterinarian Medical Association (HSVMA). Ver link: http://www.prou.cat/castellano/n.php?id noticia=34 21 legisladores mexicanos. Ver Link: http://www.prou.cat/castellano/n.php?id_noticia=32 El premio Nobel John M. Coetzee y la profesora Priscilla Cohn, viuda del filósofo Ferrater Mora. Ver linK http://www.prou.cat/castellano/n.php?id_noticia=33 Su Santidad el Dalai Lama. Ver linK http://www.prou.cat/castellano/proposta.php La World Society for the Protection of Animals (WSPA). Ver link: http://noticias.terra.es/2010/espana/0726/actualidad/entregan-en-el-parlament-140000-firmas-de120-paises-contra-las-corridas-de-toros.aspx; Antoni Tàpies, Carles Pujol Ver linK http://www.europapress.es/catalunya/noticia-antoni-tapies-carles-puyol-apoyan-abolicion-corridascatalunya-20100719115838.html 
su versión tecnológica como ética. Los avances en el conocimiento de la naturaleza y una amplia sensibilidad social por esta cuestión han hecho que nos replanteemos un nuevo posicionamiento del hombre respecto al resto de la vida del planeta. En el último cuarto de siglo, la concepción de los animales ha cambiado de manera significativa. Este pensamiento, en forma de exigencias morales, ha encontrado lugar en algunos textos legales que no parten del bienestar de los humanos, sino del bienestar de los animales, con una consideración de mínimos. El lugar que deben tener los animales, por tanto, en la moral y en el derecho, es consecuencia de una evolución social, fruto de las investigaciones de carácter científico y de la etología.

Todo sistema jurídico cumple una función de control social y de regulación de la vida en comunidad. En un mundo sin confrontaciones, diferencias y conflictos, el derecho no haría falta ya que en la solución de disputas, que varían según las sociedades, el tiempo y el espacio, radica su existencia y fin en si mismo. Las leyes son la base de la democracia y gracias a ellas la convivencia ordenada es posible. Esta función de ordenamiento social y organización permite que el derecho acepte el conflicto que tenga respaldo en la opinión pública y en el poder político, dando lugar a normas reguladoras que modelan la vida social a través del establecimiento de parámetros indicativos de lo permitido, lo prohibido y lo obligatorio. En todas las leyes se prohíben algunos comportamientos para proteger otros valores: se protege básicamente lo que es aceptable y se prohíbe fundamentalmente lo que ya no es aceptable, aunque lo haya sido en el pasado. En este caso, el derecho también es un instrumento para estimular o exhortar valores que se estiman como importantes para la sociedad.

Que una actividad sea legal no significa que no sea violenta; que esta violencia esté legalizada no es más que un agravante. Además, el hecho de que el maltrato a los animales esté institucionalizado y permitido por las autoridades públicas dificulta la protección de otros animales, como los gatos y los perros, ya que fomenta el desprecio hacia los animales y las personas se acostumbran a permanecer impasibles ante el maltrato de un ser vivo, arraigando en nuestra cultura la noción del animal como una cosa, algo con lo que nos podemos divertir, haciéndolo sufrir hasta terminar matándolo.

Las corridas de toros son una excepción a la regla general que otorga a los animales un nivel de protección mediante medidas de carácter bienestarista. Todas las leyes de protección de los animales de las Comunidades Autónomas (menos Canarias y ahora 
Cataluña) contienen en su articulado la incoherente excepción que deja al margen las corridas de toros de la prohibición de aquellos espectáculos donde se maltraten animales públicamente; incongruencia que se repite en otras esferas del ordenamiento jurídico a nivel de la Unión Europea: 1) así, la Directiva 98/58/CE del Consejo, relativa a la protección de los animales en las explotaciones ganaderas instaura ${ }^{19}$ ya en su artículo 1 idéntica desigualdad, al establecer que su mandato no se aplica a los animales destinados a participar en competiciones, exposiciones o actos o actividades culturales 0 deportivos; 2) igualmente, el conjunto de acciones que conforman el método de sacrificio ritual del toro es contrario a las exigencias legales de carácter europeo sobre esta materia, configurada por el reciente Reglamento n 1099/2009, del Consejo, de 24 de septiembre de 2009 , relativo a la protección de los animales en el momento de la matanza, ${ }^{20}$ según el cual, durante el sacrificio, no se causará a los animales ningún dolor, angustia o sufrimiento evitable, si bien se subraya la necesidad de respetar las costumbres relativas a las tradiciones culturales de los países miembros, ${ }^{21}$ y en atención a que las corridas de toros se han considerado históricamente como un acontecimiento cultural, se encontrarían dentro del ámbito de aplicación del Reglamento.

Por este motivo, resulta tan relevante que un Parlamento, de forma democrática y después de un intenso debate, social y político, haya suprimido de nuestro sistema legal esta excepción, moral y jurídicamente inadmisible.

\footnotetext{
${ }^{19}$ http://www.derechoanimal.info/bbdd/Documentos/93.pdf

${ }^{20}$ http://www.derechoanimal.info/bbdd/Documentos/733.pdf

${ }^{21}$ En la misma línea se enuncia en el Tratado de Lisboa que entró en vigor el 1 de diciembre de 2009 , el cual ha quedado redactado de la siguiente manera: "Al formular y aplicar las políticas comunitarias en materia de agricultura, pesca, transporte, mercado interior e investigación y desarrollo tecnológico y espacio, la Comunidad y los Estados miembros tendrán plenamente en cuenta las exigencias en materia de bienestar de los animales, como seres sensibles, respetando al mismo tiempo las disposiciones legales o administrativas y las costumbres de los Estados miembros relativas, en particular, a ritos religiosos, tradiciones culturales y patrimonio regional." http://www.derechoanimal.info/bbdd/Documentos/736.doc
} 